\title{
PERTENCIMENTO E IDENTIDADE EM ADOLESCENTES EM SITUAÇÃO DE RISCO DE BRASÍLIA*
}

\section{BELONGING FEELINGS AND IDENTITY OF ADOLESCENTS AT RISK SITUATION IN BRASÍLIA}

Deise Matos do Ampuro

Paola Biasoli Alces **

Carmen J. Cárdenas **

AMPARO, A. M. d; AlVES, P. B.; CARDENAS, C. J. Pertencimento e identidade em adolescentes em situação de risco de Brasília. Rev. Bras. Cresc Desenv Hum, São Paulo, 14(1), 11-20, 2004.

Resumo: Este artigo apresenta resultados parciais de uma pesquisa sobre pertencimento e identidade de adolescentes em situação de risco da cidade de Brasília. Esta pesquisa, que está em desenvolvimento, objetiva tanto explorar a visão dos adolescentes sobre pertencimento quanto discutir as relações entre pertencimento e identidade no contexto de instituições de atenção ao adolescente em termos de suas fronteiras éticas e conceitos pedagógicos. Para isso, 21 instituições foram investigadas bem como 48 de seus adolescentes. O método inclui um questionário investigando as características básicas de cada instituição e entrevista semiestruturada com adolescentes. Os resultados sugeren^$\wedge 1$ que o senso de identidade e pertencimento são vistos como importantes aspectos na vida dos adolescentes em situação de risco e que as organizações sociais que trabalham com essa população devem levar isso em consideração quando desenvolvem os seus projetos.

Palavras-chave: adolescência em situação de risco; identidade; pertencimento.

\section{INTRODUÇÃO}

\section{Caracterização da situação de risco psicossocial}

Segundo alguns autores contemporâneos (ALVES, 2002; BANDEIRA, KOLLER, KUTZ \& FORSTER, 1996; CONOLLY \& ENNEW, 1996; HAWKINS, 1986; OLIVEIRA, 1998; RAFFAELLI \& KOLLER, 2001; ROSEMBERG 1996; RUTTER, et al., 1995), as situações de risco psicossocial são enrugas pe $a^{\wedge}{ }^{\wedge} \operatorname{lvenc}^{\wedge}$ la cotidiana de fatores estressantes associados à miséria económica (falta de saneamento básico, desemprego, marginalidade) e, também, à miséria afetiva (maus tratos como abandono, negligência, violên- cia fisica, psíquica e sexual), devendo ser entendidas de acordo com pressupostos sistêmicos de desenvolvimento humano. A generalidade desta definição pode ser compreendida melhor de acordo com a situação específicavivenciada pelos adolescentes moradores das Regiões Administrativas de Brasília, público-alvo da pesquisa realizada.

A capital do Brasil, antes mesmo de coinpletar dez anos, já havia extrapolado o número de 500 mil habitantes - população ideal estimada em seu plano original. Desde a sua construção, ocorreram invasões sucessivas de terrenos ao redor do chamado Plano Piloto e, para atender ao crescente número de migrantes sem especialização de mão-de-obra, com baixa escolaridade e

\footnotetext{
* Projeto de Pesquisa financiado pela UCB/PETROBRÁS. Desenvolvimento do trabalho apresentado no IX ${ }^{\mathrm{EME}}$ CONGRÈS INTERNATIONAL DE L' ARIC 2003 - L' ADOLESCENT EN SITUATION DE RISQUE IDENTTITÉ ET CULTURE D' APARTENANCE.

** Professoras de Psicologia da Universidade Católica de Brasília - UCB - Correspondência: SGA No 916 Módulo B, Avenida W5, Asa Norte. CEP 70790-160. E-mail: deise@ucb.br
} 
de baixo poder aquisitivo que chegavam à Brasília, foram surgindo as “cidades satélites”, pequenos aglomerados de casas precariamente construídas em espaços sem asfalto, luz, água encanada e condições de saneamento básico.

O fluxo migratório de outros estados em direção à Brasília repetiu (e repete) a busca de uma parcela da população por melhores condições de vida, incluindo oportunidades de emprego e assistência adequada de seus direitos relativos à educação, ao lazer, à cultura e à saúde. Entretanto, tal movimento também significa perdas sucessivas: da terra, do trabalho, da tutela e dos elos familiares. Diante da inviabilidade da realização de projetos mobilizadores da migração em uma perspectiva do desenvolvimento humanamente sustentável, o Distrito Federal passa a conhecer uma população marginalizada de pessoas cada vez mais jovens. Há uma grande parcela da população de adolescentes que vivencia cotidianamente riscos perpetuados pelas situações de exclusão econômica e social e com evidentes possibilidades de ter seu desenvolvimento emocional prejudicado, se comparada a outros jovens da mesma faixa etária que não vivem sob tais condições adversas. Para a pesquisa aqui apresentada foram identificadas como representativas desta situação as Regiões Administrativas de Taguatinga e Ceilândia. Contudo, é fundamental ressaltar que a dimensão do risco (seja este vivido como fator de estresse, seja presente enquanto potencial de vulnerabilidade) não anula, em absoluto, a naturalidade do movimento do desenvolvimento no ciclo vital, ou seja, estes jovens, assim como quaisquer outros, têm como tarefa no seu desenvolvimento as delimitações de seus parâmetros de identidade, a estruturação de sua vivência sexual e a busca crescente de intimidade e autonomia no campo afetivo e do trabalho, construindo e fortalecendo redes de apoio sócio-afetivo.

Em relação aos adolescentes em situação de risco psicossocial percebe-se que há a possibilidade da história de seus pais, assim como a sua, ser marcada por pobreza econômica e afetiva, por separações difíceis, por rupturas de vínculos, pelas perdas de difícil elaboração e, também, pela crise cultural que coloca em questão a própria definição do papel do adolescente e da família (LEVISKI, 2001). A realidade social e psicológica desses adolescentes também apresenta experiências como a exposição à violência, ao abandono, às drogas, aos maus tratos entre outras, evidenciando padrões específicos de desenvolvimento cognitivo e sócio-emocional dentro dos processos de resiliência e vulnerabilidade. A promoção e realização da resiliência são caracterizadas pela retomada do desenvolvimento saudável após vivências estressantes e podem ser estimu- ladas por características pessoais favoráveis e pela qualidade e coesão entre os ambientes sociais. Já o processo de vulnerabilidade caracteriza-se pela presença do risco pessoal ou social dentro das possibilidades de identificação, estruturação e vivência de psicopatologias e sintomas somáticos, mostrando as dificuldades de enfrentamento adequado e eficaz às situações estressantes vividas (ALVES, 2002; APTEKAR, 1994; GARMEZY \& MASTEN, 1994; HAWKINS, 1986; HECHT, 1998; KOLLER \& HUTZ, 1996; LUCCHINI, 1993; MARTINS, 1996; RIZZINI, 1986; RUTTER, 1993).

\section{$O$ adolescer: identidade e pertencimento}

Dentro da compreensão sistêmica do desenvolvimento adolescente, abrangendo parâmetros físicos, cognitivos e emocionais, um aspecto significativo que vem se evidenciando a partir de estudos sobre a adolescência é a complexidade da qual se reveste a questão da identidade. Esta é mantida não apenas nos níveis intra e intersubjetivo (pessoal e familiar), mas, também, nas dimensões social, cultural e histórica.

No contexto dessa discussão alguns autores (ERIKSON, 1972; LEVISKY, 1995; BLOS, 1995) salientam que o desenvolvimento da identidade e do eu é tarefa crucial na adolescência, envolvendo a combinação das identificações infantis do passado com as transformações fisicas, sociais e emocionais presentes e os compromissos futuros numa unidade pessoal integrada. Nesse sentido, a identidade é um construto pessoal e social variável, associado à diversidade sócio-cultural que apresenta valores, crenças, regras e padrões e se faz em um processo contínuo caracterizado por períodos críticos do desenvolvimento que se organizam de forma dinâmica. Ainda que a qualidade específica da identidade de uma pessoa difira de cultura para cultura, a resolução desta tarefa no desenvolvimento é elemento comum a todas as culturas humanas (MWSS, 1988). Com o objetivo de adquirir uma identidade definida e saudável, a criança e, posteriormente, o adolescente, deve receber reconhecimento consistente e coerente de suas potencialidades e conquistas.

A identidade organiza-se na confluência do individual e do social, portanto, implica o próprio eu (self) e o outro nas suas várias representações como a família, os pares, as instituições e a comunidade. A noção de identidade relaciona-se, nesse sentido, ao pertencimento e, portanto, tem um caráter ao mesmo tempo individual estrutural (quando ligado à apropriação do corpo próprio, representação de si e imagem do corpo) e social, 
quando relacionada às dimensões de vinculação ao outro e territorialização. Visto dessa forma, o laço social ocupa um lugar fundamental na construção da identidade, particularmente no decurso da adolescência. Além da configuração simbólica do indivíduo, o meio cultural conforma e constrói a identidade particular, pois ela se estabelece como diferença cultural frente ao grupo.

Na cultura brasileira, atualmente, tradições e costumes não exercem formalizações ritualísticas que, eventualmente, ajudariam o adolescente a resolver com tranqüilidade as exigências que lhe são demandadas pela sociedade. Isto significa que ele deve realizar com seus recursos pessoais a adaptação e a integração no ambiente social, em um processo de desenvolvimento individual de diferenciação psicológica.

Considera-se que as relações familiares, entre pares e com os outros, implicam uma vivência emocional e afetiva dos adolescentes, sendo que estas estão intimamente relacionadas ao seu desenvolvimento pessoal, participando e refletindo-se no processo de constituição da sua identidade (CARDENAS, 2000). Coloca-se, assim, a necessidade de ampliação da análise da adolescência de uma perspectiva individual para a situacional, havendo a integração do outro e do contexto nos quais os jovens devem realizar o seu caminho no processo de construção da identidade. Essa reflexão sobre a multiplicidade de fatores intervenientes na construção da identidade possibilitará a estruturação de estratégias de atenção a estes adolescentes que considerem sua especificidade e psicologia, definindo-se, dessa forma, intervenções mais adequadas à sua realidade, principalmente no que se refere à promoção de resiliência nos contextos de vivências de risco psicossocial. Dentro deste contexto, as representações que os adolescentes em situação de risco tem sobre si mesmos, sua família, os vínculos entre pares e as referências institucionais trazem informações significativas sobre esses universos relaeionais na vida do adolescente e, por conseqüência, sua importância nas relações de pertencimento e identidade. Estas representações são sempre constitutivas, elas apresentam a construção do mundo tal como ele é conhecido e as identificações que ela sustenta garantem um lugar nesse mundo. É essa dupla operação de definir o mundo e localizar um lugar nele que fornece às representações o seu valor simbólico (DWEEN, 1995). Enquanto processo psicossocial a construção da identidade é um modo de organizar significados que possibilita à pessoa posicionar-se enquanto ator social. Neste sentido, ABRIC (2003) ressalta o papel que as representações desempenham não só na constituição da identidade pes- soal, como também na identidade social, principalmente quando se referendam aos atos educativos, ou seja, as representações sociais são diretamente influentes nas práticas educativas.

Esse trabalho apresenta e discute dados de uma pesquisa que, dentro de seu projeto de longo alcance, pretende ser uma pesquisa-ação, e que tem como objetivo geral mapear as características do atendimento institucional e as representações de pertencimento dos adolescentes atendidos pelas instituições periféricas de Brasília, das regiões de Ceilândia e Taguatinga. Visa, também, discutir a relação entre o pertencimento e a identidade do adolescente e a ética institucional, abrangendo as concepções pedagógicas do trabalho pelas instituições realizado e as práticas efetivadas.

Pretende-se conhecer a situação dos serviços de atenção ao adolescente e as representações das relações de pertencimento pessoal, familiar e social desses jovens atendidos pelas instituições, considerando-se que as indicações desses sistemas podem salientar práticas de promoção de resiliência e proteção para o desenvolvimento saudável. Sabe-se que os projetos sociais que atendem aos adolescentes em situação de risco exigem uma atenção particular às relações de pertencimento e identidade desses jovens. Isso implica em realizar investigações que conduzam ao reconhecimento dos recursos pessoais dos adolescentes que possam fundamentar a direção das ações em direção a essa população.

Ao se explicitar esta relação entre as situações c e risco psicossocial e os parâmetros de vivência adolescente procura-se, através dos dados coletados nesta pesquisa, delimitar as questões de identidade e pertencimento familiar e nos grupos de pares dos adolescentes, assim como as temáticas dos projetos pedagógicos e a ética das instituições que podem funcionar como fatores de proteção no seu desenvolvimento, caracterizando-se conceitos como rede de apoio sócio-afetivo, processos de interação, constituição de identidade e promoção de resiliência.

\section{MÉTODO}

Para a realização da etapa de pesquisa aqui descrita foram delimitados dois núcleos de coleta de dados: a) uma amostra de instituições que atendem a adolescentes em situação de risco psicossocial nas áreas de Taguatinga e Ceilandia e b) uma amostra dos adolescentes atendidos por estas mesmas instituições.

Participaram da coleta de dados 21 instituições com programas de atendimento a adolescentes em situação de risco das Regiões Admi- 
nistrativas de Taguatinga e Ceilândia, distribuídas entre a modalidade de abrigamento (instituição que auxilia no cumprimento de medidas protetivas previstas no Estatuto da Criança e do Adolescente - ECA - nos casos de violação dos Direitos da Criança e do Adolescente) e sócioeducativa (instituição que auxilia no cumprimento de medidas protetivas e sócio-educativas - previstas no caso de infrações - presentes no ECA).

A amostra da pesquisa, também foi composta por 48 adolescentes, sendo 41 do sexo masculino e 07 do sexo feminino participantes das atividades e programas das 21 instituições pesquisadas. O grupo foi composto de forma aleatória com o consentimento dos adolescentes.

Foram utilizados os seguintes instrumentos e procedimentos para coleta de dados:

1) Ficha de cadastro - elaborada com o objetivo de ser preenchida por telefone, contendo os dados cadastrais iniciais da instituição como endereço, tipo de registro, mantenedoras, diretor, etc. Foram cadastradas 43 instituições e através do preenchimento das fichas foi feita a seleção das instituições que participariam da etapa seguinte, considerando critérios de representatividade como Organizações Governamentais, Organizações Não Governamentais, Religiosas e Filantrópicas.

2) Roteiro de entrevista semi-estruturada - este roteiro foi elaborado com o objetivo de identificar e descrever os procedimentos institucionais de acordo com parâmetros éticos e pedagógicos, focalizando as atividades propostas e realizadas com os adolescentes, os contatos interinstitucionais, corpo de funcionários e voluntários, dificuldades e práticas efetivas dentro do atendimento em rede (saúde, educação, profissionalização), contato com a família dos adolescentes, entre outras temáticas. As 21 instituições que compuseram esta etapa da pesquisa foram contatadas por telefone, as entrevistas marcadas com a pessoa indicada pela instituição e realizadas na mesma por um dos pesquisadores. As entrevistas foram gravadas e transcritas literalmente.

3) Questionário para ser preenchido individualmente pelos adolescentes em encontros de pequenos grupos, com questões que abordam as temáticas da identidade, do pertencimento familiar e no grupo de pares, assim como questões relativas à escolaridade, profissio- nalização, drogas, DST/AIDS, paz e violência e em relação ao cotidiano vivido dentro das instituições. Todas as questões eram abertas sendo que se previa a livre expressão dos adolescentes sobre os temas.

As entrevistas realizadas nas instituições, assim como os questionários preenchidos pelos adolescentes foram submetidos a: análises estatísticas de descrição (freqüência, média, porcentagens); análise do conteúdo através do modelo quantitativo-interpretativo que prevê a criação de categorias de respostas por aproximação de conteúdo com critérios de exaustão e exclusividade no sentido de cada uma; e, finalmente, análise de conteúdo através do softvvare ALCESTES, que permite a identificação de temas recorrentes e seus significados no corpo de dados.

\section{RESULTADOS E DISCUSSÃO}

\section{Os adolescentes e as referências de pertencimento}

De acordo com os 48 adolescentes em situação de risco que responderam ao questionário e que são atendidos nos programas sócioeducativos das instituições pesquisadas das regiões periféricas de BrasIlia, são possíveis de identificação quatro categorias de representação sobre a família e seu papel, mostrando a natureza dos vinculas e trazendo informações significativas sobre os universos relacionais em suas vidas. Estas categorias de referência e suas definições são: cooperação/apoio (categoriacaracterizada pela presença de respostas nas quais a família é identificada como fonte de apoio nas mais diversas situações e/ou cujos membros vivenciam experiências de cooperação e suporte); afetiva (categoria caracterizada pela presença de respostas nas quais a família é identificada através da expressão de sentimentos de afeto); parentesco (categoria caracterizada pela presença de respostas nas quais a identificação da família é feita pela citação dos laços de parentesco consangüíneos) e positiva global (categoria caracterizada pela presença de respostas nas quais os adolescentes avaliam de forma positiva as relações vividas no contexto familiar).

Como pode ser verificado no Gráfico 1, os adolescentes representam o papel da família enfocando prioritariarnente as referências de cooperação/apoio (37\% das respostas), as refèrências afetivas (25\% das respostas), a referência positiva global (23\% das respostas) e, por fim, as referências ao parentesco ( $13 \%$ das respostas), ou- 
tros - não se encaixam nas categorias anteriores ( $2 \%$ de respostas). Pode-se perceber que, para esses adolescentes que frequentam instituições de abrigo e/ou sócio-educativas e convivem com situações de uso de drogas, maus tratos, aios delinquentes, a família é representada primordialmente por ideais de cooperação e apoio. Este dado mostra que, embora vivam em situações sociais de vulnerabilidade, para estes jovens a família ainda é uma referência de pertencimento que pode contribuir para a organização da identidade. Em suas falas o aspecto positivo sempre é ressaltado: «te ajuda mesmo que você não presta», «se unem em momentos dificeis», «traz segurança», «divisão de coisas boas e ruinso, «onde aprendo a viveis>.

Nos dados relativos às relações de amizade, identificou-se que os adolescentes as representam com referências de cooperação/ apoio, afetivas, de confiança (categoria que caractenza a presença de respostas nas quais os dolescentes paz de guardar segredossitiva global e confiança,

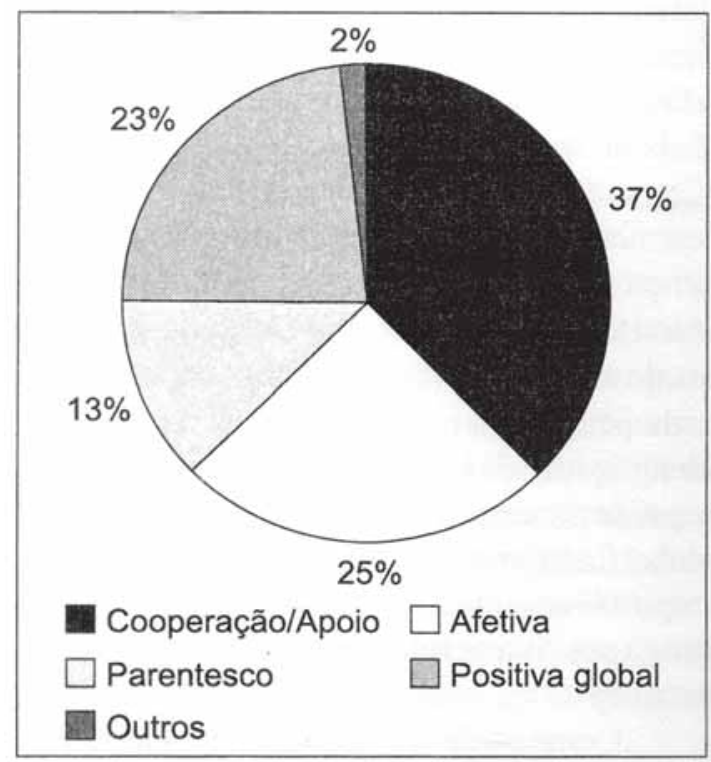

Gráfico 1. Distribuição, em percentual, das referências dos adolescentes sobre a familia.

Sobre o início e estabelecimento das relações de amizade os dados indicam que $27 \%$ desses adolescentes encontram seus pares no ambiente escolar, $24 \%$ na rua, $13 \%$ na instituição, ^9\% na igreja, $7 \%$ em cursos, $4 \%$ na vizinhança, $4 \%$ na família, $4 \%$ outros, 3\% em atividades de lazer, 3\% não respondeu e $2 \%$ no trabalho, Nota-se que a escola e a rua são pontos de referência importantes para o desenvolvimento de relações de identificação entre pares. As relações de amizade implicam a e fornecer infonmações), referência po aquele ca salientando o papel do amigo relatam a amizade como fonte de segurança e como representações de vulnerabilidade/proteção (categoria caracterizada pela presença de respostas nas quais os adolescentes citam os amigos como aqueles que podem favorecer o desenvolvimento saudável - proteção - ou prejudica-lo - vulnerabilidade). A maior parte das representações, apresentadas no Gráfico 2, situamse nas referências à cooperação apoio (32\% das respostas), à confiança (29\% das respostas), afetivas (13\% das respostas) ao parentesco (3\% das respostas), positiva global (3\% das respostas) e outros 14\%. Em suas falas esses aspectos são evidenciados «pessoa que está sempre ao seu lado», "prazer de cuidar», «ajuda na hora dito cil», «com quem se abre», «conte ança», «nao ser falso e nem desonesto». Poucas vezes o aspecto da vulnerabilidade proteção é indicado (6\% das respostas), sendo representado em frases como «andassem usar drogas», «é bom mas nem sempre leva a algum lugar»"

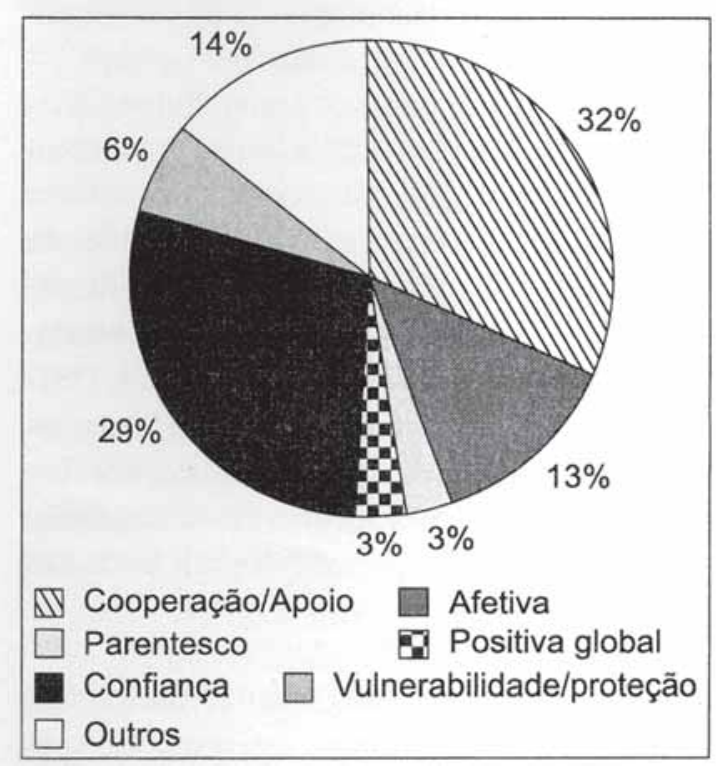

Gráfico 2. Distribuição, em percentual, das referências dos adolescentes sobre os pares.

uma vivência emocional e afetiva entre os adolescentes, estando intimamente integradas ao seu desenvolvimento pessoal, participando e refletindose no processo de sua constituição subjetiva.

Na discussão destes dados pode-se citar o estudo de Ecologia Social nas escolas, realizado por COLEMAN ( 1974), no qual descreveu uma "sociedade adolescente", indicando que os estudantes preferiam apoiar-se nos companheiros mais do que procurar apoio nos pais e ainda, os valo- 
res aceitos eram diametralmente opostos àqueles praticados pela instituição familiar e escolar. $\mathrm{O}$ estudo desse autor marcou e criou uma imagem da assim chamada "cultura dos grupos de adolescentes” que foi rapidamente aceita pela sociedade em geral, incluindo os meios de comunicação e a midia. Assim, de fonna equivocada, creditouse ao adolescente características claramente definidas que, aparentemente, expressam conformidade e submissão às regras do "grupo”. Contudo, estudos mais recentes sugerem evidências contrárias a estas afirmações, indicando que os adolescentes são profundamente influenciados pelos pais, com freqüência tanto quanto o são pelos companheiros e, ainda, indicam a multiplicidade e a diversidade que caracterizam seus modelos de comportamento e sistema de valores (BROWN et al., 1993; STEINBERG, et al., 1992). Os dados coletados neste estudo evidenciam a importância do contato social amplo para a estruturação das relações de amizade e indicam o papel de proteção que estas desempenham, uma vez que são definidas, principalmente, pelas características de cooperação/apoio, projetando uma perspectiva de uma rede sócio-afetiva com características de afetividade.

BUKOWSKI (1998) considera que se deve pesquisar o papel das redes sociais, isto é, a família, o meio escolar e, num sentido mais amplo, a cultura, uma vez que suas propriedades e estruturas têm relevante papel na formação do indivíduo. LEVISKY (2001) demonstra que, por meio dos vínculos presentes nestas redes podem ser construídas perspectivas de desenvolvimento saudável, enfatizando a integração entre aspectos ambientais e pessoais. Neste sentido são relevantes as vivências do adolescente na família, a construção de espaços de liberdade e responsabilidade pessoal, o desenvolvimento da capacidade de resistência à frustração, a priorização do protagonismo juvenil na busca de soluções e a transformação do ato educativo em um processo de co-responsabilidade (família-jovem-comunidade).

A rede das relações dos companheiros e dos amigos oferece amplas oportunidades para negociações com os outros sobre os planos, dúvidas, objetivos pessoais e oferece aceitação e suporte, de forma que as competências pessoais são estimuladas ou expandidas, respondendo às necessidades da vida atual. HARTUP e SANCILIO (1986, citado em BUKOWSKI, 1998) sugerem que a vivência da amizade fornece um contexto para o crescimento de competências sociais, disponibilizando segurança emocional e suporte, além de funcionar como predecessor de relações afetivas posteriores. Considerando a perspectiva de redes sociais, as vivências afetivas com ami- gos ajudam os adolescentes a superar interações pobres com as figuras parentais, assim como seus efeitos negativos em comportamentos no contexto social. Assim, ao se discutir estes dados iniciais sobre as representações dos adolescentes sobre sua família, seus amigos e as possibilidades de locais de vivência das relações com os pares, a perspectiva da promoção de resiliência fortifica-se nos aspectos dos relacionamentos interpessoais, na dinâmica de interações entre indivíduo-ambiente social como realizadora de proteção no âmbito sócio-emocional do adolescente e catalisadora na construção de recursos internos (psíquicos) inerentes ao processo de desenvolvimento saudável, caracterizando-se como fonte primordial de apoio. Independentemente da qualificação da representação familiar (categoria), esta é sempre identificada como mantenedora de aspectos sócio-emocionais de qualidade, assim como os amigos, em mais de $70 \%$ das respostas dos adolescentes. Ainda, é fundamental salientar que a estrutura das representações apresentada pelos adolescentes não difere das esperadas para qualquer indivíduo neste processo, o que valoriza a perspectiva do desenvolvimento no ciclo vital e a investigação de parâmetros contextuais para a construção de programas de intervenção. Ao se viabilizar a expressão destes jovens sobre seu cotidiano de relações, as estereotipias e o preconceito vinculados ao que pode significar viver em situação de risco são esclarecidos e podem auxiliar em processos saudáveis de desenvolvimento integral.

Na análise dos dados pertinentes ao segundo foco abordado neste artigo, considerando-se a instituição como parte da rede social de referência (13\% indicam a instituição como fonte de contatos sociais), os adolescentes indicam que preferem, entre os serviços e oportunidades sociais oferecidos pelas instituições: as atividades esportivas e de lazer (18\%), o ensino (17\%), os profissionais da instituição (17\%), as pessoas (8\%), os amigos (6\%), alimentação (4\%), tudo (4\%), outros (13\%), não responderam (13\%). Em relação ao que menos gostam na instituição, $17 \%$ das regras e horários e 14\% da má interação dos colegas, $8 \%$ das pessoas, $4 \%$ das atividades, $4 \%$ da estrutura, 4\% das atividades de lazer, 4\% trabalhos domésticos, 14\% não responderam, 19\% disseram gostar de tudo e $12 \%$ outros - categoria que não se encaixa nas anteriores.

Os dados mostram que, de maneira geral, as atividades promovidas e os contatos sociais estabelecidos no cotidiano das instituições são caracterizados de forma satisfatória pelos adolescentes, devendo-se salientar a dupla qualificação quando estes se referem às interações com os co- 
legas (estas são valorizadas por 6\% da amostra e apresentam-se como dificuldade para 14\% da mesma). A necessidade de obediência às regras mostra-se como aspecto de desagrado, contudo, este dado reforça a idéia de generalidade do processo de desenvolvimento adolescente, sendo que o questionamento das regras e, certo grau de dificuldade em obedecê-las, relaciona-se com aspectos saudáveis da constituição da identidade dos indivíduos, desde que estas regras sejam informadas e sua desobediência possa ser argumentada.

\section{O ATENDIMENTO AO ADOLESCENTE E A ÉTICA INSTITUCIONAL}

Como já descrito, os adolescentes da pesquisa fazem parte da população atendida por instituições de Ceilândia e Taguatinga - regiões periféricas de Brasília que oferecem abrigamento e atenção sócio-educativa. As 21 instituições entrevistadas, do total de 43 cadastradas que trabalham com adolescentes em situação de risco, atendem um total de 1434 jovens.

De acordo com os dados coletados, a modalidade de atendimento a esta população é distribuída de forma equivalente entre abrigamento e atenção sócio-educativa, sendo que 75\% das instituições são de caráter filantrópico/religioso, 10\% são governamentais, 10\% são filantrópico/não-religioso e 5\% são Organizações Não Governamentais (ONGs). As instituições oferecem atendimento aos jovens nas seguintes modalidades: $52 \%$ em sistema de abrigamento, 28\% atividades sócio-educativas e $20 \%$ estão distribuídas entre atividades de profissionalização, tratamento de dependência química e atividades artístico-culturais.

A finalidade, ou seja, o compromisso ético social dessas instituições inclui, segundo seu próprio relato: assistência social, atendimento a famílias em situação de vulnerabilidade, recuperação de drogadictos, promoção do exercício da cidadania, atividades sócio-educativas, oferta de cursos profissionalizantes, oferecimento de condições para que as pessoas busquem vivenciar a cidadania, disponibilizar abrigamento. Na complementação destes dados, estas mesmas instituições consideraram como sua missão: amor ao próximo, reabilitação, construir urna nova esperança, reforço da auto-estima dos adolescentes, desenvolver o espírito humano de solidariedade e crescimento, proteção e promoção social, realização de um trabalho social moral e doutrinário.

Embora as finalidades e as missões das instituições componham uma série de objetivos muitas vezes complexos que demandariam uma orientação metodológica e avaliativa processual, é relevante apresentar que, das instituições entrevistadas apenas três relatam que dispõem de um projeto pedagógico ou de atendimento, sendo estes: 1. «Piaget, descoberta, desenvolvimento da criatividade e habilidades», 2. «Trabalhamos com a cultura popular brasileira, o projeto pedagógico é intrínseco a essa produção popular, um sistema co-cooperativo, partimos do pressuposto que todos tem algo para ensinar e para aprender», 3. «Pedagogia da presença, busca o lado positivo da criança». Percebe-se que, embora representem uma grande força no trabalho de assistência aos direitos fundamentais dos jovens, de maneira geral, as instituições aqui pesquisadas apresentam projetos pedagógicos pouco consistentes, de características intuitivas mais do que fortificadas em dados legitimados em experiências e pesquisas dentro do contexto que abrange os parâmetros de desenvolvimento saudável da população atendida, havendo a mistura de referênciais pedagógicos e psicológicos muitas vezes conflitantes em suas bases epistemológicas.

A análise de conteúdo do discurso dos profissionais das instituições, realizada com o software $A L C E S T E$, apresenta a prevalência de três classes que demonstram a preocupação desses profissionais com o serviço que oferecem e prestam. A classe 1 refere-se ao plano mais amplo de intervenção da instituição e agrupa falas que tratam de «projetos e programas pedagógicoeducativos», com peso discursivo de 36,8\%; a classe 2 refere-se a crenças e valores que permeiam a concepção do atendimento institucional agrupa falas que consideram a «ideologia do atendimento institucional», com peso discursivo de 16,26\%; e a classe 3 refere-se a atividades desenvolvidas no cotidiano da instituição e considera as falas que dizem respeito a «atuação da instituição», com peso discursivo 47,66\%. Na última classe, que apresenta maior peso discursivo, sobressai na fala dos profissionais a ausência de apoio político, técnico e instrumental para atuação efetiva, dificuldades em relação às atividades desenvolvidas, ao trabalho com fatores de risco (drogas e violência), ao desenvolvimento de projeto de futuro dos adolescentes, à rede de parcerias para receber e encaminhar o adolescente.

Questionados sobre «como podem contribuir na formação do adolescente?» os profissionais desenvolvem seu discurso enfocando basicamente cinco categorias: educar (28\%), profissionalizar (21\%), acolher (17\%), desenvolver competências subjetivos (13\%) e disciplinar (8\%), não informou (13\%). Fica evidenciado que a educação e a profissionalização ainda são preocupações fundamentais dos educadores que desenvolvem um trabalho enfocando a instrumen- 
talização e o acolhimento. No entanto, ao não desenvolver uma perspectiva de desenvolvimento integral e de protagonismo juvenil, desvaloriza-se a perspectiva de promoção de resiliência, que prevê o estímulo da autonomia, da valorização dos fatores de proteção nos âmbitos das características pessoais e das interações sociais.

\section{ADOLESCÊNCIA, INSTITUICÕES E REDES DE APOIO SOCIO-AFETIVO}

Sistematizando os dados apresentados em conjunto (adolescentes e instituições), considera-se que a construção da identidade está relacionada, também, ao contexto sócio-cultural e à vinculação ao outro que, no caso do presente estudo, está relacionada à freqüência nas instituições. No trabalho com adolescentes em situação de risco é, portanto, fundamental compreender a ética institucional e como as instituições se relacionam com a subjetividade e pertencimento do jovem. O educador tem função ímpar no trabalho com estes adolescentes, tendo a tarefa de restabelecer laços do adolescente com o mundo adulto e as instituições (SANTOS \& COSTA, 2001). Assim, as instituições de atenção aos adolescentes em situação de risco, em consonância com uma posição ética que implica realizar um trabalho efetivo e eficaz com esses jovens, deve levar em consideração o adolescente como um todo, suas competência subjetivas e redes de pertencimentos. Os processos de subjetivação possibilitam a cada ator social vir a se tornar sujeito no centro de um sistema social humanizado e humanizante. Em outras palavras, o sujeito está integrado, ao mesmo tempo, em uma pessoa singular e em conjuntos sociais.

Nessa pesquisa os dados mostram que, embora vivam em situações sociais de vulnerabilidade, estes jovens têm na família e nas relações de amizade referências de pertencimento, assim como significam um papel de proteção uma vez que são definidas, principalmente, pelas características de cooperação/apoio, projetando, assim, uma perspectiva de rede sócio-afetiva. As instituições, enquanto rede de apoio, quando têm profissionais bem e continuamente formados e uma proposta pedagógica consistente, podem se constituir em fontes de proteção e desenvolvimento da resiliência, exercendo o papel de ambiente sócio-emocional rico na diversidade, estimulando aspectos como respeito, tolerância, disciplina, rotinas integradas e produtivas, interações pessoa-pessoa com características de valorização da inter e intrasubjetividades com significações criticas e construtivas da realidade, efetivando, assim, seu lugar de promoção de apoio, proteção e transformação.

Fortalecendo estes aspectos, ao considerar as funções das redes sociais SLUZKI (1997) cita, entre outros pontos, o apoio emocional e a regulação social. No que diz respeito ao primeiro aspecto ressalta a importância do apoio emocional referindo-se a intercâmbios que mobilizam uma atitude emocional positiva, clima de apoio, compreensão, empatia, o que significa poder contar com a ressonância einocional. Estas possibilidades encontram-se expressas nas opiniões dos adolescentes quando estes referendam tanto o papel da família como o dos amigos em suas vidas. No que se refere à ressonância emocional, SLUZKI (1997) ressalta a importância das interações que lembram e reafirmam as responsabilidades e papéis de cada ator social, permitindo uma dissipação das frustrações e das violências. Neste sentido, os dados descritos neste trabalho mostram a disponibilidade dos jovens pesquisados em colocar-se em relações de cooperação/apoio e de características afetivas positivas, aspectos fundamentais para vivenciar interações saudáveis e recíprocas. Ainda, as instituições entrevistadas demonstram a fragilidade de determinantes pedagógicos e psicológicos no seu trabalho, sem, contudo, deixar de se responsabilizar por participar da vida cotidiana destes jovens com o intuito de fazer a diferença quanto à promoção e resiliência em suas vidas.

Aprofundando esta discussão, visando, inclusive, legitimar parâmetros de prognóstico, a Teoria dos Sistemas Ecológicos, iniciada por BRONFENBRENNER (1979/1996, 1993, 1995) na década de 70 , evidencia a necessidade de que, para a promoção e efetivação de um desenvolvimento saudável, portanto, para a realização da resiliência em processos de situação de risco, é necessário que os ambientes de interação social favoreçam espaços de afeto, reciprocidade e equilíbrio de poder, caracterizando-se, assim, como microssistemas de qualidade. Neste sentido, a resiliência estaria atuando através das características pessoais favoráveis e estruturadas (auto-estima, competência social) e da qualidade e coesão entre os ambientes sociais. Dentro destes microssisteinas, privilegiando estes aspectos, os adolescentes podem desenvolver processos proximais onde internalizarão conteúdos simbólicos referentes à convivência em sociedade e ao fortalecimento de suas características pessoais, culminando no exercício efetivo de sua cidadania e, conseqüentemente, na melhoria da qualidade de vida. Desencadeado e mantido este processo de interação de qualidade, há a imple- 
mentação do desenvolvimento na rede de apoio sócio-afetivo, que será beneficiada de toda a sistemática de promoção de saúde integral do adolescente, incluindo-se neste processo as famílias, as escolas e demais microssistemas frequentados pelos jovens.

Também, dentro de uma perspectiva ecológica de desenvolvimento humano, é fundamental estar atento para a formação continuada dos educadores que convivem cotidianamente com adolescentes em situação de risco, principalmente pela multideterminação que envolve as situações de miséria econômica e afetiva, sendo que estes profissionais devem estar sistematicamente desenvolvendo habilidades de relacionamento interpessoal e de crítica transformadora das situações presenciadas. Sua atuação junto aos jovens é caracteristicamente microssistêinica, assim, seu valor é indiscutível enquanto mediadores dos processos de promoçao de resliência.

\section{CONSIDERAÇÕES FINAIS}

Os dados apresentados permitem identificar as representações dos adolescentes sobre suas redes de pertencimento e as considerações das instituições sobre o atendimento prestado, salientando-se, nas primeiras, as perspectivas de construção de redes favoráveis ao seu desenvolvimento e, nas demais, as questões que oscilam entre o compromisso social e o assistencialismo, parâmetros contemporâneos dos aspectos de execução de políticas públicas de proteção e sócio-educação de adolescentes no país. Pode-se inferir, com os resultados dessa pesquisa, que os projetos sociais que trabalham com os jovens em situação de risco devem qualificar a construção da identidade e do pertenciinento dado que valorizar o sujeito e suas redes sociais de referência contribui potencialmente como fator de proteção e desenvolvimento da resiliência.

\begin{abstract}
Social projecta lo assist adolescente at risk situation need to pay particular attention to lhe belonging culture that is shared by them. This paper aims to present data from 21 care institutions and 48 adolescents at risk situation assisted by programs from the Administrative Regions of Brasília - Taguatinga and Ceilândia -, Federal District, Brazil. It proposes characterizing the institutions' social and ethical commitment and identifying characteristics of the adolescents' representations of personal, family and social belonging that can contribute to their identity constitution. We believe that these system indicators favor the constitution of social-affective supporting networks that promote health. The data were analyzed in an integrated model with descriptive statistic aspects, quantitative-interpretative analysis, and content analysis by means of the Sof ware ALCESTE.
\end{abstract}

Key-word: adolescence at risk; identity; belonging feelings.

\section{REFERÊNCIAS BIBLIOGRÁFICAS}

Abric JC. Representações sociais e fenômenos de exclusão. In: IV Encontro Nacional - I Encontro Internacional Violência, Exclusão Social e Desenvolvimento Humano. (Conferência não publicada). Jun. 2003. Brasília: Universidade de Brasília.

Alves PB. Infância, tempo e atividades cotidianas de crianças em situação de rua: as contribuições da Teoria dos Sistemas Ecológicos [tese]. PortoAlegre (RS): Instituto de Psicologia da Universidade Federal do Rio Grande do Sul, 2002.

Aptekar L. Street children in the developing world: a review of their condition. Cross Cultural Research 1994, (28): 195-224.

Bandeira DR, Koller SH, Kutz CS, Forster L. Desenvolvimento psicossocial e profissionalização: uma experiência com adolescentes de risco. Psicologia Reflexão e Crítica 1996, 9(1): 185-207.
Blos P. Adolescência: uma interpretação psicanalítica. São Paulo: Martins Fontes, 1995.

Bronfenbrenner U. The ecology of cognitive development: research models and fugitive findings. In: Wozniak R, Fischer D, editors. Development in context, acting and thinking in specific environments. Hillsdale (NJ): Erlbaum, 1993. p.3-44.

Bronfenbrenner U. Developmental ecology through space and time: a future perspective. In: Moen PM, Elder GH, Lüscherk, editors. Examining, lives in context. Washington (DC): American Psychological Association, 1995.

Bronfenbrenner U. A ecologia do desenvolvimento humano: experimentos naturais e planejados. Porto Alegre: Artes Médicas, 1996.

Brown B, Mounts N, Lamborn S, Steinberg L. Parenting practices and peer group affiliation in adolescence. Child Development 1993, 64: 467-82.

Bukowski WM. The company they keep: friendship in childhood and adolescence. Cambridge: Cambridge University Press, 1998. 
Cardenas JC. Adolescendo: um estudo sobre a constituição da identidade do adolescente no âmbito da escola [tese]. Brasília (DE): Instituto de Psicologia da Universidade de Brasília, 2000.

Coleman JS. Relationships in adolescence. Boston: Routledge, Kegan Paul, 1974.

Conolly M, Ennew J. Children out of place [introduction]. Childhood 1996, 3: 131-45.

Duveen G Crianças enquanto atores sociais: as representações sociais do desenvolvimento. In: Guareschi, PA, Jovchelovitch S, organizadores. Textos em representações sociais. Petrópolis: Vozes, 1995.

Erikson EH. Identidade, juventude e crise. Rio de Janeiro: Zahar, 1972.

Garmezy N, Masten A. Chronic adversities. In: Rutter M, Taylor E, Herson L, editores. Child and adolescent psychiatry. Oxford: Blackwell Scientific Publication, 1994. p. 191-207.

Hawkins P. Children at risk: my fight against child abuse. A personal story and public plea. Bethesda: Adler, Adler, 1986.

Hecht T. At home in the street: street children of northeast of Brazil. Cambridge: Cambridge University Press, 1998.

Koller SH, Hutz CS. Meninos e meninas em situação de rua: dinâmica diversidade e definição. Coletânea da ANPEPP 1996, í(12): 5-12.

Levisky D. Adolescência: reflexões psicanalíticas. Porto Alegre: Artes Médicas, 1995.

Levisky D, organizador. Adolescência e violência: ações comunitárias na prevenção. Conhecendo, articulando, integrando e multiplicando. São Paulo: Casa do Psicólogo, 2001.

Lucchini R. Enfant de la rue: identite, sociabilité, drogue. Genève: Librairie Droz, 1993.

Martins RA. Censo de crianças e adolescentes em situação de rua em São José do Rio Preto. Psicologia Reflexãoe Crítica 1996, 9(1): 101-22.

Muuss RE. Theories of adolescence. $5^{\text {th }}$ ed. New York: Random House, 1988.

Oliveira EA. Modelos de risco na psicologia do desenvolvimento. Psicologia: Teoria e Pesquisa 1998, 14: 19-26.
Raffaelli M, KollerSH. Street children's rights and wellbeing: psychological, behavioral and policy concerns. Newsletter of International Society for the Study of Behavioural Development 200í: (2): 3-5

Rosemberg F. Estimativa de crianças e adolescentes em situação de rua: procedimentos de uma pesquisa. Psicologia Reflexão e Crítica 1996, 9(1): 21-58.

Rutter M, Champion L, Quinton D, Maughan B, Pickles, A. Understanding individual differences in environmental-risk exposure. In: Moen PM, Elder GH, Lüscher K, editors. Examining lives in context. Washington: American Psychological Association,1995. vol.1, p. 6193.

Rizzini I. A geração de rua: um estudo sobre a criança marginalizada no Rio de Janeiro. Rio de Janeiro (RJ): Cesme/Universidade Santa Ursula, 1986.

Rutter M. Resilience: some conceptual considerations. Journal of Adolescent Health 1993, 14: 626-31.

Sluski CE. A rede social na prática sistêmica São Paulo: Casa do Psicólogo, 1997.

Santos IA, Costa CH. LAC - Liberdade e acesso à cultura: uma proposta sócio educativa para os adolescentes em conflito com a lei. In: Levisky D, organizador. Adolescência e violência: ações comunitárias na prevenção. Conhecendo, articulando, integrando e multiplicando. São Paulo: Casa do Psicólogo, 2001.

Steinberg L, Lamborn SD, Dornbusch SM, Darling N. Impact of parenting practices on adolescent achievement: authoritative parenting, school involvement, and encouragement to succeed. Child Development 1992, 63: 1266-81.

Recebido em 22/08/2003

Modificado em 23/10/2003

Aprovado em 02/12/2003 